\title{
Undeclared animal species in dry and wet novel and hydrolyzed protein diets for dogs and cats detected by microarray analysis
}

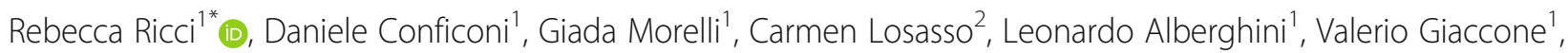
Antonia Ricci $^{2}$ and Igino Andrighetto ${ }^{1}$

\begin{abstract}
Background: Although the European Pet Food Industry Federation (FEDIAF) stated that labels must be accurate and provide detailed information on the ingredients, mislabeling of pet food has been documented by several authors. This phenomenon is of particular concern when related to products used as elimination diets for the diagnosis of adverse food reaction (AFR) in dogs and cats because the presence of undeclared ingredients may negatively interfere with the trial and prevent the veterinarian from making an appropriate diagnosis. The aim of this study was to shed light upon the problem of contamination and mislabeling in both dry and wet novel protein diets (NPDs) and hydrolyzed protein diets (HPDs) using a microarray-based commercial kit which tests for the presence of 19 animal species.

Results: Of the 40 analyzed products ( 9 dry NPDs, 22 wet NPDs, 6 dry HPDs and 3 wet HPDs), ten presented a content that correctly matched the label, while five did not contain the declared animal species, twenty-three revealed the presence of undeclared animal species, and two had a vague label that did not allow the evaluation of its accuracy. The most frequently contaminants identified in both dry and wet pet foods were pork, chicken and turkey. The presence of undeclared animal species was higher in dry than wet pet foods; furthermore, a lower number of contaminating animal species was identified in HPDs than NPDs (4 vs 10), and a lower number of contaminated HPDs (6 out of 9, 67\%) than contaminated NPDs was detected (24 out of 31, 77\%). Thirteen out of 14 brands tested presented at least one mislabeled product.

Conclusions: Mislabeling seems to be a widespread issue in pet foods used as elimination diets. Contamination can occur in all types of products used for the purpose, although dry NPDs are the main issue. Due to the high risk of contamination, particular attention should be given to both the selection of raw material suppliers and the production process.
\end{abstract}

Keywords: Pet food, Meat species identification, Novel protein diet, Hydrolyzed protein diet, Mislabeling, Species substitution, Adverse food reaction

\footnotetext{
* Correspondence: rebecca.ricci@unipd.it

'Department of Animal Medicine, Production and Health, Viale Dell'Università

16, 35020 Legnaro, Italy

Full list of author information is available at the end of the article
}

(c) The Author(s). 2018 Open Access This article is distributed under the terms of the Creative Commons Attribution 4.0 International License (http://creativecommons.org/licenses/by/4.0/), which permits unrestricted use, distribution, and reproduction in any medium, provided you give appropriate credit to the original author(s) and the source, provide a link to the Creative Commons license, and indicate if changes were made. The Creative Commons Public Domain Dedication waiver (http://creativecommons.org/publicdomain/zero/1.0/) applies to the data made available in this article, unless otherwise stated. 


\section{Background}

Mislabeling is an important concern for people who require a controlled diet, and the issue has recently arisen in regard to dog and cat food as well. In a study conducted in the United Kingdom, when testing for the presence of bovine, chicken, porcine and horse DNA in 17 popular wet pet foods obtained from supermarkets, Maine et al. [1] observed that cow, pig and chicken were included in 15 products even when not explicitly stated on their labels. Similarly, when testing a wide range of dog and cat foods $(n=52)$ available in the US market (from both retail and online stores) for the presence of mitochondrial DNA of eight different animal species (i.e. bovine, caprine, ovine, chicken, goose, turkey, porcine, and equine), Okuma and Hellberg [2] found that $38.5 \%$ of pet foods were potentially mislabeled because they either contained meat species not declared in the label or did not contain meat species that were. The pet food samples included in the studies by Maine et al. [1] and by Okuma \& Hellberg [2] were intended for the maintenance of dogs and cats. A more particular concern has been raised recently regarding the mislabeling of pet food products specifically formulated to contain a single source of protein (novel protein diets, NPDs) [3-5], which along with hydrolyzed protein diets (HPDs) are used as elimination diets for the diagnosis of adverse food reaction (AFR) in dogs and cats. The rationale behind these two dietary approaches is clearly explained in the review by Verlinden et al. [6].

Since dietary trial is the only reliable method to diagnose AFR [7], the presence of undeclared animal species in NPDs and HPDs is a major concern when feeding a food-hypersensitive dog or cat an unpredictably contaminated product because any potentially allergenic protein may preclude significant remission of symptoms and mislead the clinician in diagnosing AFR [4]. Elimination diets, both NPDs and HPDs, are also used in dogs with chronic enteropathies to diagnose food-responsive diarrhea (FRD), antibiotic-responsive diarrhea (ARD) and steroid-responsive disease (SRD) on the basis of the dog's response to treatment $[8,9]$.

When considering studies focused on the presence of contaminants in commercial elimination diets, Raditic et al. [3] used an ELISA method to test four over-the-counter venison canine dry foods for the presence of soy, poultry and beef; Ricci et al. [4] analyzed twelve canine dry pet foods used as dietary elimination trials with three zoological classes in mind (i.e. mammal, poultry and fish) via both PCR and a microscopy protocol, whereas in the study by Horvath-Ungerboeck et al. [5], a real time PCR test was used on seven dry and five wet pet foods to identify five animal species (i.e. chicken, turkey, beef, mutton and pork).

Due to the higher stability of DNA molecules compared to proteins when exposed to high temperature,
DNA-based protocols seem to be the most reliable methods for the identification of animal species in highly processed foods such as pet food [10].

In the three studies mentioned above, the protocols used for animal species identification were time-consuming and focused on detecting a limited number of animal species in a small number of canine pet food samples, most of which (23 out of 28 ) were dry [1-5].

The aim of this study was to shed light upon the problem of contamination and mislabeling in dry and wet pet foods used as elimination diets for the diagnosis of canine and feline AFR. Unlike the aforementioned studies, the current investigation adopted a rapid DNA-based microarray for the detection of 19 animal species in a single run. The presence of a contaminant was assumed whenever an animal species not declared in the ingredient list was detected by microarray analysis.

\section{Methods \\ Sample recruitment}

A total of 40 pet foods (15 dry and 25 wet) for dogs $(n=36)$ and cats $(n=4)$ produced by 14 different producers were collected from the market. The samples included single batches of 31 NPDs (9 dry and 22 wet) and 9 HPDs (6 dry and 3 wet). Pet foods labels were carefully read to identify every source of protein and fat in the ingredients list. From each pet food, an aliquot of $50 \mathrm{~g}$ was sampled and sent to the laboratory for animal species identification. All the analyses were performed in the Food Microbiology laboratory of the Istituto Zooprofilattico Sperimentale delle Venezie (Legnaro, Italy).

\section{Animal species identification}

All samples were treated according to the GeneTop Meat-V kit protocol (GeneTop, Taiwan -R.O.C.). The procedure is an accredited method of the Istituto Zooprofilattico Sperimentale delle regioni Lazio e Toscana M. Aleandri [11]. The protocol is based on the extraction of the total DNA fraction, the amplification of specific DNA targets via polymerase chain reaction (PCR), and subsequent DNA microarray assay on solid matrix.

\section{DNA extraction}

An aliquot of $200 \mathrm{mg}$ of either homogenized wet pet food or ground dry pet food was sampled under sterile conditions in duplicate for each product. The samples were processed for DNA extraction using the DNeasy mericon food kit (QIAGEN, Hilden, Germany) according to manufacturer instructions. DNA quality and concentration were assessed after extraction by spectrophotometer (SmartSpec ${ }^{\text {TM }}$ Plus spectrophotometer, Bio-Rad, USA). 


\section{DNA amplification and microarray assay}

The reagents used for amplification and hybridization were all supplied with the GeneTop Meat-V kit (GeneTop, Taiwan - R.O.C.). Briefly, amounts of $22.25 \mu \mathrm{l}$ of Meat-IV Mix and $0.25 \mu \mathrm{l}$ of Taq were transferred in sterile PCR tubes kept at low temperature. PCR samples were prepared by adding $2.5 \mu \mathrm{l}$ of the previously extracted DNA to the reaction mix. PCRs were carried out in a GeneAmp PCR System 9700 (Applied Biosystem, USA) using the following PCR protocol: $2 \mathrm{~min}$ at $94{ }^{\circ} \mathrm{C}$ followed by 30 cycles of $94{ }^{\circ} \mathrm{C}$ for $30 \mathrm{~s}, 60^{\circ} \mathrm{C}$ for 30 s, and $72{ }^{\circ} \mathrm{C}$ for 30 s. A final elongation step was performed at $72{ }^{\circ} \mathrm{C}$ for $10 \mathrm{~min}$. The amplified samples were then stored at $-20^{\circ} \mathrm{C}$ until use.

\section{Microarray analysis}

The microarray plate was designed to detect the presence of 19 animal species: bovine, buffalo, cat, chicken, dog, donkey, duck, hare, fish, goat, goose, horse, mice, porcine, poultry, rabbit, rat, sheep, turkey.

The protocol used for microarray identification was supplied by the manufacturer (GeneTop, Taiwan - R.O.C.). Briefly, the amplicons obtained by PCR were denatured by heating to $95{ }^{\circ} \mathrm{C}$ for $5 \mathrm{~min}$ and $30 \mathrm{~s}$, then placed on ice. The pre-warmed (to room temperature) HA Buffer was pipetted in advance in each Meat-V Chip well and the liquid was spread over the surface of every chip. A $5 \mu \mathrm{l}$ amount of the denatured amplicons was loaded in each well, and then the biochip was covered with adhesive film. The biochip was then incubated at $50{ }^{\circ} \mathrm{C}$ for $40 \mathrm{~min}$ in the hybridization shaker (1000 rpm). The hybridization liquid was discarded and the wells were washed three times using $200 \mu \mathrm{l}$ of Wash buffer. The Blocking reagent was prepared with a StrepAP and B buffer ratio of 1:1000, and a total $100 \mu \mathrm{l}$ of the mixture was poured into each well and incubated for $20 \mathrm{~min}$ at $50{ }^{\circ} \mathrm{C}$. The biochip was washed 3 times with $200 \mu \mathrm{l}$ of Wash buffer and then $200 \mu \mathrm{l}$ of $\mathrm{C}$ buffer was added and discarded. The detection buffer composed of $2 \mu \mathrm{l}$ of NBT/BCIP mixed with $98 \mu \mathrm{l}$ of $\mathrm{C}$ buffer (ratio 1:50) was added to each well and the biochip was placed in the dark for 7 min. The detection buffer was discarded and the chip was rinsed with tap water twice. The dried biochip was then read using the GeneTop reader (GeneTop, Taiwan - R.O.C.) and by naked eye. According to the manufacturer, the test sensibility is $0.1 \%$. The results were recorded in a Microsoft Excel spreadsheet (Microsoft Corporation, Redmond, WA).

\section{Results}

The following animal species were detected in at least one sample of the pet foods tested: bovine, chicken, duck, fish, goat, goose, horse, pork, poultry, rabbit, sheep and turkey. The following species instead were not detected in any sample: buffalo, cat, dog, donkey, hare, mice and rat.
The results obtained by DNA-based microarray assay are shown in Table 1.

The composition of 38 out of 40 samples was indicated on the label by a list of ingredients that clearly allowed the identification of the animal species included, whereas the remaining two product labels used terms like 'animal proteins' in sample ID 8 and 'hydrolyzed offal' in sample ID 15 that did not permit such identification. Despite their positivity for two and five animal species respectively, it was therefore impossible to state the inadequacy of these two product labels. For all the other 38 pet foods, label adequacy was evaluated as follows. Ten samples (one dry and nine wet; seven NPDs and three HPDs) were labeled correctly because only the DNA of the protein source stated in the ingredient list was detected (sample IDs: 14, 16, 18, 23-25, 27, 31, 35, 36). Five samples (one dry and four wet; four NPDs and one HPDs) were mislabeled because the DNA of the protein source stated in the ingredient list was not detected (sample IDs: 2, 17, 19, 28, 37); in particular, in three samples (ID 2,17,19) duck was not detected, in sample ID 28 the salmon declared on the label did not trigger positivity for fish, and in sample ID 37 the hydrolyzed poultry liver specified on the label did not trigger the positivity expected either for chicken, turkey, or even poultry. In the remaining 23 samples, the DNA of the protein source stated in the ingredient list was detected, but the DNA of one to seven other protein sources not listed on the label was detected as well (Fig. 1).

Table 2 shows the number of dry and wet pet foods positive to an animal species not declared on the label.

The contaminants most frequently identified by the microarray kit in dry pet foods were pork, chicken, poultry and turkey, followed by bovine, fish and ovine, then horse; on the other hand, the least common contaminants were duck and goat. Regarding wet pet foods, pork was the most common contaminant, followed by chicken, poultry, turkey, bovine and sheep; the least common contaminant was horse, while fish, duck and goat were not detected in these samples.

Since the microarray used in this study lacked a deer DNA detection well, it was impossible to both confirm the presence of venison in the three samples that listed such species on the label and identify venison contamination in the others.

In general, one dry sample out of 13 and nine wet samples out of 25 did not show any DNA contamination from animal species not listed on the label.

Fewer animal species not listed on the label were identified in HPDs than in NPDs (4 vs 10, Fig. 1); moreover, a higher number of contaminated HPDs (6 out of 9, $67 \%$ ) than contaminated NPDs was detected (24 out of 31, 77\%). More details are reported in Table 3. 


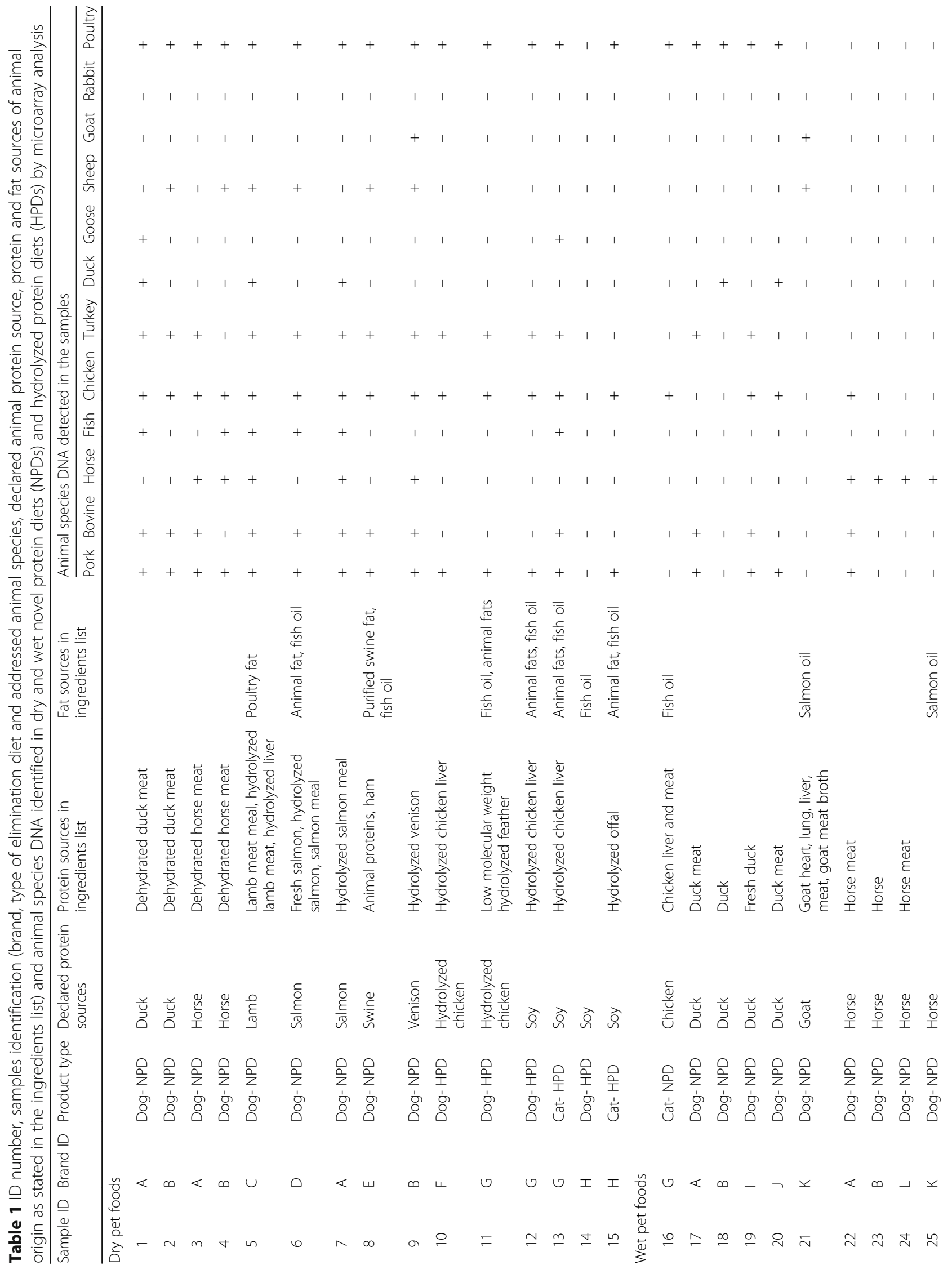




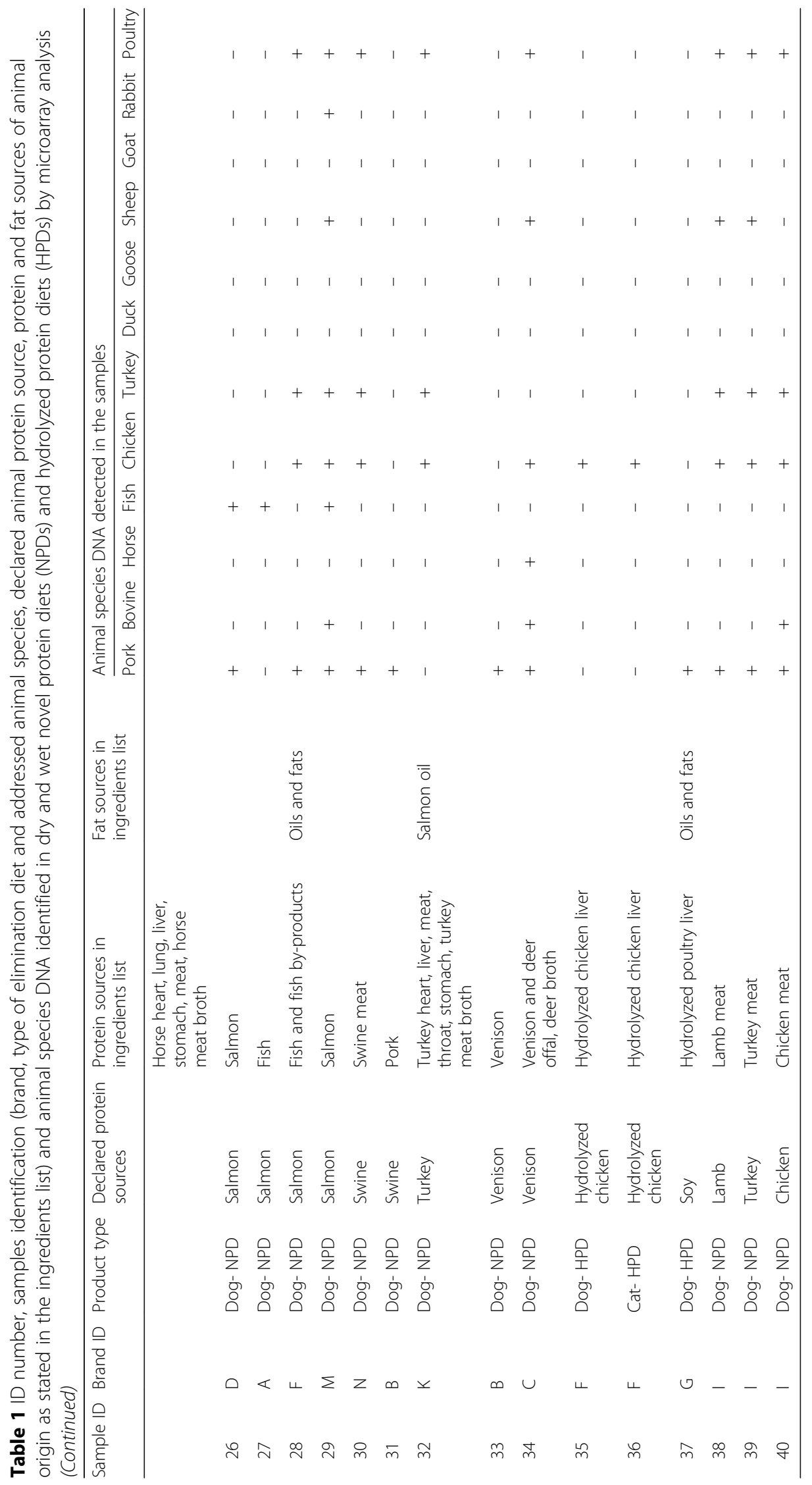




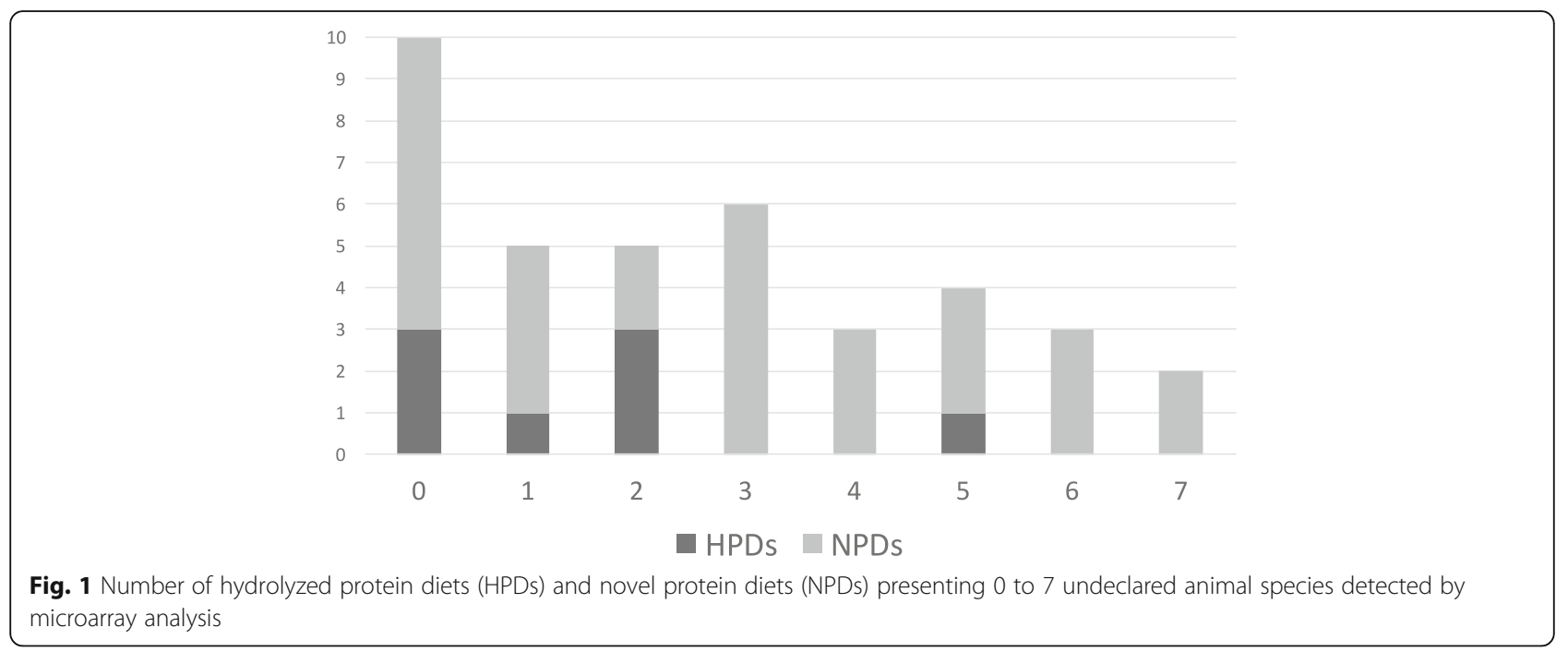

In HPDs, the most common contaminants detected by microarray analysis were pork, turkey, bovine and fish. Pork, chicken, poultry, turkey, bovine and sheep were the most common contaminants in NPDs.

With the exception of brand L, at least one mislabeled product was identified in all the brands considered (Table 4).

\section{Discussion}

As stated by the European Pet Food Industry Federation (FEDIAF [12]), pet food labels must be accurate and all ingredients unequivocally identified. This is particularly important for pet foods formulated as elimination diets for the purpose of diagnosing an adverse food reaction in dogs or cats because the accuracy of the label and correspondence with the ingredients actually included in the formula assume paramount importance in the success of the trial.

In this study, we performed microarray analysis on a total of 40 products formulated for dietary elimination trials in order to investigate possible contaminants and mislabeling. The ingredient list of samples ID 8 and ID 15 provided vague indications of meat content (i.e. 'animal proteins' and 'hydrolyzed offals', respectively), thereby precluding the identification of the animal species listed on label by reading alone. Therefore, any animal species may have been included, and although microarray analysis of these two products detected more than one species, the non-adequacy of the products cannot be stated with more accuracy. European Regulation

Table 2 Number and percentage (\%) of dry and wet pet foods in which animal species not listed on the label were detected

\begin{tabular}{|c|c|c|c|c|}
\hline & DRY pet foods & & WET pet foods & \\
\hline $\begin{array}{l}\text { Animal species detected } \\
\text { by the microarray }\end{array}$ & $\begin{array}{l}\text { Number of pet foods in } \\
\text { which the animal species } \\
\text { was not listed in the label }\end{array}$ & $\begin{array}{l}\text { Number and } \% \text { of pet foods } \\
\text { in which such unlisted } \\
\text { species was detected }\end{array}$ & $\begin{array}{l}\text { Number of pet foods } \\
\text { in which the animal } \\
\text { species was not listed } \\
\text { in the label }\end{array}$ & $\begin{array}{l}\text { Number and \% of pet } \\
\text { foods in which such } \\
\text { unlisted species was } \\
\text { detected }\end{array}$ \\
\hline Sheep & 12 & $4(33.3 \%)$ & 24 & $4(16.7 \%)$ \\
\hline Duck & 11 & $2(18.2 \%)$ & 21 & $0(0 \%)$ \\
\hline Bovine & 13 & $8(61.5 \%)$ & 25 & $6(24 \%)$ \\
\hline Goat & 13 & $1(7.7 \%)$ & 24 & $0(0 \%)$ \\
\hline Goose & 15 & $1(6.7 \%)$ & 24 & $0(0 \%)$ \\
\hline Horse & 11 & $3(27.3 \%)$ & 21 & $1(4.8 \%)$ \\
\hline Pork & 13 & $12(92.3 \%)$ & 23 & $13(56.5 \%)$ \\
\hline Chicken $^{a}$ & 9 & 8 (88.9\%) & 20 & $10(50 \%)$ \\
\hline Poultry ${ }^{b}$ & 7 & $6(85.7 \%)$ & 14 & $5(35.7 \%)$ \\
\hline Fish & 11 & $4(36.4 \%)$ & 21 & $0(0 \%)$ \\
\hline Turkey & 13 & 11 (84.6\%) & 23 & 7 (30.4\%) \\
\hline
\end{tabular}

${ }^{a}$ chicken or hydrolyzed chicken was declared on the label

${ }^{b}$ chicken, turkey, hydrolyzed chicken or duck or goose was declared on the label 
Table 3 Number and percentage (\%) of hydrolyzed protein diets (HPDs) and novel protein diets (NPDs) in which animal species not listed on the label were detected

\begin{tabular}{|c|c|c|c|c|}
\hline & HPDs & & NPDs & \\
\hline $\begin{array}{l}\text { Animal species detected } \\
\text { by the microarray }\end{array}$ & $\begin{array}{l}\text { Number of pet foods in } \\
\text { which the animal species } \\
\text { was not listed in the label }\end{array}$ & $\begin{array}{l}\text { Number and \% of pet } \\
\text { foods in which such } \\
\text { unlisted species was } \\
\text { detected }\end{array}$ & $\begin{array}{l}\text { Number of pet foods } \\
\text { in which the animal } \\
\text { species was not listed } \\
\text { in the label }\end{array}$ & $\begin{array}{l}\text { Number and \% of pet } \\
\text { foods in which such } \\
\text { unlisted species was } \\
\text { detected }\end{array}$ \\
\hline Sheep & 8 & $0(0 \%)$ & 28 & $8(28.6 \%)$ \\
\hline Duck & 8 & $0(0 \%)$ & 24 & 2 (8.3\%) \\
\hline Bovine & 8 & $1(12.5 \%)$ & 30 & $13(43.3 \%)$ \\
\hline Goat & 8 & $0(0 \%)$ & 29 & $1(3.4 \%)$ \\
\hline Goose & 8 & $0(0 \%)$ & 29 & $1(3.4 \%)$ \\
\hline Horse & 8 & $0(0 \%)$ & 24 & $4(16.7 \%)$ \\
\hline Pork & 8 & $5(62.5 \%)$ & 28 & $20(71.4 \%)$ \\
\hline Chicken $^{a}$ & 1 & $0(0 \%)$ & 28 & $18(64.3 \%)$ \\
\hline Poultry ${ }^{b}$ & 1 & $0(0 \%)$ & 20 & 11 (55\%) \\
\hline Fish & 8 & $1(12.5 \%)$ & 24 & $3(12.5 \%)$ \\
\hline Turkey & 8 & $4(50 \%)$ & 28 & $14(50 \%)$ \\
\hline
\end{tabular}

achicken or hydrolyzed chicken was declared on the label

bchicken, turkey, hydrolyzed chicken or duck or goose was declared on the label

(EC) No 767/2009 [13] allows categories of ingredients to be listed on pet food labels, and many pet food products take advantage of this option. However, vague ingredient lists should not be acceptable in pet foods intended for the diagnosis of adverse food reactions. All the remaining 38 products had detailed ingredient lists, and meat species were clearly reported in their labels.

According to microarray results, only $25 \%$ of the products analyzed were suitable for effective AFR diagnosis. Although these findings demonstrate that producing an

Table 4 Number of mislabeled and correctly labeled dry and wet pet foods divided by brand

\begin{tabular}{lllll}
\hline & \multicolumn{2}{l}{ DRY pet foods } & WET pet foods \\
\hline Brand ID & Mislabeled & Correctly labeled & Mislabeled & Correctly labeled \\
A & 3 & 0 & 2 & 1 \\
B & 3 & 0 & 1 & 3 \\
C & 1 & 0 & 1 & 0 \\
D & 1 & 0 & 1 & 0 \\
E & 1 & 0 & 0 & 0 \\
F & 1 & 0 & 1 & 2 \\
G & 3 & 0 & 1 & 1 \\
H & 1 & 1 & 0 & 0 \\
I & 0 & 0 & 4 & 0 \\
J & 0 & 0 & 1 & 0 \\
K & 0 & 0 & 2 & 1 \\
L & 0 & 0 & 0 & 1 \\
M & 0 & 0 & 1 & 0 \\
N & 0 & 0 & 1 & 0 \\
\hline
\end{tabular}

uncontaminated pet food is possible, three out of four commercial elimination diets would not be useful in allowing the clinician to obtain precise AFR diagnosis.

The five mislabeled samples whose declared animal species were not detected by the micro-array analysis can be construed as a commercial fraud punishable by law with additional complications for producers other than leading to mistaken diagnosis for food allergic animals. Samples listed as containing duck (ID 2,17,19) were instead positive to both poultry and chicken and/or turkey, and this may be considered intentional substitution with cheaper ingredients of avian origin. Commercial frauds in pet foods were reported in a previous study by Okuma and Hellberg [2] where six products were not found to contain the meat species declared on the front of the package.

On the other hand, the consequences of including undeclared animal species in elimination diets have already been presented elsewhere [4]. The presence of one to multiple animal species not declared on the label of elimination diets was demonstrated by a PCR-based approach in previous studies $[4,5]$, whereas the microarray analysis performed here was able to identify up to 19 animal species in a single run.

The most common animal species not declared on the labels of both dry and wet pet foods were pork, chicken and turkey. In the study by Horvath-Ungerboeck et al. [5], the most common contaminants were beef (positive in $8 / 12$ samples) and pork (positive in 6/12 samples). Since pork, poultry and beef are the animal species most commonly slaughtered in Europe for human consumption [14], they are the ones that provide the largest 
amount of animal by-products to pet food manufacturers. Given that their meat is cheaper than that of other species like duck, venison, and goat, economic reasons may underline the frequent detection of these animal species as contaminants, as suggested by Okuma and Hellberg [2]. This may also be the reason why goat and duck were the contaminating animal species least frequently identified in this study. These species were not investigated in the recent study by Horvath-Ungerboeck et al. [5], which considered only five animal species (chicken, turkey, beef, mutton and pork).

Our results showed that undeclared animal species were more commonly found in dry than wet pet foods. This is in contrast with the results by Okuma and Hellberg [2] in which the rate of mislabeled wet foods $(n=12 / 16)$ was higher than that of mislabeled dry pet foods (2/17). In a study by Ricci et al. [4] in which only dry pet foods were included, no comparison between dry and wet diets was possible, whereas Horvath-Ungerboeck et al. [5] analyzed 8 dry complete diets and 4 canned (2 complete and 2 complementary) products, in which 6 dry (75\%) and 3 canned (75\%) resulted mislabeled. One possible reason for the more frequent contamination observed in dry products could be that the technological process does not allow thorough cleaning between the production of consecutive batches. Another reason might regard the quality of the incoming raw materials: the dehydrated meat meals used in dry pet food production may be contaminated with other different meat meals during production, transport or storage. Whether this is a more significant possibility for meat meals than the meat-derivatives used for wet pet food production remains conjecture.

HPDs have been investigated less in previous studies on contamination in elimination diets: there was only 1 HPD in the 12 elimination examined in the study by Ricci et al. [4] and only 2 HPDs in the 12 pet foods studied by Horvath-Ungerboeck et al. [5]. In the present study that includes 9 HPDs, stronger conclusions can be drawn. It may therefore be stated that fewer contaminating animal species were identified in HPDs than in NPDs and a lower number of contaminated HPDs was detected than NPDs. Even hypothesizing that producers take extra care when producing HPDs, contamination of hydrolysed raw material at their production site (and therefore prior to delivery to the pet food plant) or during transportation cannot be excluded. The present results demonstrated that even if pork was not mentioned in their ingredient list, five HPDs were positive to swine DNA. One of these five products labels stated "hydrolyzed animal offals" in the ingredient list, which does not exclude the presence of pork; however, the remaining four were chicken- and/or soy-based products. There is no way of knowing whether the swine DNA detected was derived from hydrolysed or non-hydrolysed swine protein or even swine fat; this notwithstanding, these samples were not listed as containing swine DNA and this can be construed as contamination. Since HPDs are used as elimination diets for the ARF diagnosis, contamination implies that the same consequences hypothesized for contaminated NPDs be taken into consideration. This means that both HPDs and NPDs may pose problems in the diagnosis of AFR.

Although only few products were collected for some brands (only one product for four brands and only two products for three brands), it may be stated that as observed in 13 of the 14 brands tested, mislabeling is a widespread phenomenon.

\section{Conclusions}

In conclusion, microarray analysis suggested that in a survey of 38 pet food products formulated for the diagnosis of AFR in dogs and cats, 3 out of 4 were contaminated with one to seven animal species not listed on the label. This appears to be an issue that regards both novel and hydrolyzed protein diets, with a higher number of contaminating animal species being detected in the former. Contamination also seems to occur more predominantly in dry than wet products, regardless of pet food producer. Particular attention should be given to both the production process due to the high risk of cross-contamination and the selection of raw material suppliers. Bearing this in mind, these results reflect the contamination of only the batches collected here, and therefore the mislabeling of a specific product cannot be generalized either to the respective producer's previous or future productive lots. Importantly, this study demonstrates that the production of uncontaminated products is possible, as confirmed by the ten pet foods (26\%) that analysis found to be correctly labeled. When an adverse food reaction is suspected, a home-made elimination diet may be a reasonable alternative to commercial products because it allows a stricter control of the ingested ingredients and highly reduces the risk of contaminants that pose risks to the correct diagnosis of AFR.

\section{Abbreviations \\ AFR: Adverse food reaction; HPDs: Hydrolyzed protein diets; NPDs: Novel protein diets \\ Funding \\ This study was self-funded. \\ Availability of data and materials \\ The datasets analyzed during the current study are available from the corresponding author on reasonable request.}

\section{Authors' contributions}

RR: Planning of the study, support data analysis and preparation of manuscript. DC: Running of laboratory analyses, support data analysis and preparation of manuscript. GM: Support data analysis and preparation of 
manuscript. CL: Support laboratory analyses and support data analysis. LA: Support laboratory analyses and support data analysis. VG: Support laboratory analyses and support data analysis. AR: Support laboratory analyses and support data analysis. IA: Planning of the study, support data analysis. All authors read and approved the final manuscript.

\section{Ethics approval and consent to participate}

Not applicable.

\section{Consent for publication}

Not applicable.

\section{Competing interests}

The authors declare that they do not have any competing interests.

\section{Publisher's Note}

Springer Nature remains neutral with regard to jurisdictional claims in published maps and institutional affiliations.

\section{Author details}

'Department of Animal Medicine, Production and Health, Viale Dell'Università 16, 35020 Legnaro, Italy. ${ }^{2}$ Department of Food Safety, Istituto Zooprofilattico Sperimentale delle Venezie, Viale Dell'Università 10, 35020 Legnaro, Italy.

Received: 27 February 2018 Accepted: 18 June 2018

Published online: 27 June 2018

\section{References}

1. Maine IR, Atterbury R, Chang K-C. Investigation into the animal species contents of popular wet pet foods. Acta Vet Scand. 2015;57:7.

2. Okuma TA, Hellberg RS. Identification of meat species in pet foods using a real-time polymerase chain reaction (PCR) assay. Food Control Elsevier Ltd. 2015;50:9-17.

3. Raditic DM, Remillard RL, Tater KC. ELISA testing for common food antigens in four dry dog foods used in dietary elimination trials. J Anim Physiol Anim Nutr (Berl). 2011;95:90-7.

4. Ricci R, Granato A, Vascellari M, Boscarato M, Palagiano C, Andrighetto I, et al. Identification of undeclared sources of animal origin in canine dry foods used in dietary elimination trials. J Anim Physiol Anim Nutr (Berl). 2013;97(1): 32-8

5. Horvath-Ungerboeck C, Widmann K, Handl S. Detection of DNA from undeclared animal species in commercial elimination diets for dogs using PCR. Vet Dermatol. 2017;28:1-6.

6. Verlinden A, Hesta M, Millet S, Janssens GPJ. Food allergy in dogs and cats: a review. Crit Rev Food Sci Nutr. 2006;46:259-73.

7. Mueller RS, Olivry T. Critically appraised topic on adverse food reactions of companion animals (4): can we diagnose adverse food reactions in dogs and cats with in vivo or in vitro tests? BMC vet res. BioMed Central. 2017:13:275.

8. Mandigers PJJ, Biourge V, Van Den Ingh TSGAM, Ankringa N, German AJ. A randomized, open-label, positively-controlled field trial of a hydrolyzed protein diet in dogs with chronic small bowel enteropathy. J Vet Intern Med. 2010;24:1350-7.

9. Allenspach K, Culverwell C, Chan D. Long-term outcome in dogs with chronic enteropathies: 203 cases. Vet Rec. 2016;178:368.

10. Ballin NZ, Vogensen FK, Karlsson AH. Species determination - can we detect and quantify meat adulteration? Meat Sci. 2009;83:165-74.

11. Accredia. Accredited tests databank [Internet]. 2016 [cited 2018 Feb 14]. Available from: http://services.accredia.it/accredia_labsearch.jsp?ID_LINK= 293\&area $=7$ \&numeroacc $r=0201 \&$ classification $=$ M\&isRestricted $=$ false\&dipartimento $=\mathrm{L}$.

12. European Pet Food Industry Federation (FEDIAF). Code of Good Labelling Practice for Pet Food; 2011. p. 1-63.

13. Council of the European Union. Regulation (EC) No 767/2009 of the European Parliament and of the Council of 13 July 2009. Off J Eur Union. 2009:1-28.

14. FAO. FAOSTAT [Internet]. http://www.fao.org/faostat. 2018 [cited 2018 Feb 14]. Available from: http://www.fao.org/faostat/en/\#compare

\section{Ready to submit your research? Choose BMC and benefit from:}

- fast, convenient online submission

- thorough peer review by experienced researchers in your field

- rapid publication on acceptance

- support for research data, including large and complex data types

- gold Open Access which fosters wider collaboration and increased citations

- maximum visibility for your research: over $100 \mathrm{M}$ website views per year

At BMC, research is always in progress.

Learn more biomedcentral.com/submissions 